\title{
Predator-baiting experiments for the conservation of rock-wallabies in Western Australia: a 25-year review with recent advances
}

\author{
J. E. Kinnear ${ }^{\mathrm{A}, \mathrm{F}}$, C. J. Krebs ${ }^{\mathrm{B}}$, C. Pentland ${ }^{\mathrm{C}}$, P. Orell ${ }^{\mathrm{D}}$, C. Holme $^{\mathrm{E}}$ and R. Karvinen $^{\mathrm{E}}$ \\ ANumber 9, Valley Road, Wembley Downs, WA 6019, Australia. \\ ${ }^{B}$ Institute for Applied Ecology, University of Canberra, Canberra, ACT 2601, Australia. \\ ${ }^{\mathrm{C}}$ School of Natural Sciences, Edith Cowan University, 270 Joondalup Drive, Joondalup, WA 6027, Australia. \\ DEnvironmental Management Branch, Department of Environment and Conservation, Dick Perry Avenue, \\ Kensington, WA 6150, Australia.

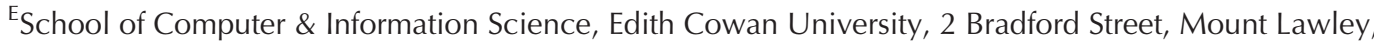 \\ WA 6050, Australia. \\ FCorresponding author. Email: jakinn2@bigpond.com
}

\begin{abstract}
Predation is widely believed to be the main threatening process for many native vertebrates in Australia For 25 years, predator-baiting experiments have been used in the Western Australian Central Wheatbelt to control red fox predation on rock-wallabies and other endangered marsupial prey elsewhere. We review here the history of a series of baiting experiments designed to protect rock-wallaby colonies by controlling red foxes with 1080 poison baits. We continue to support the conclusion that red foxes can reduce or exterminate rock-wallaby populations in Western Australia. Research trials from 1990 to 2008 have uniformly shown a dramatic recovery of rock-wallaby populations once red foxes are baited. Baiting experiments are often black boxes and their success should not blind us to their weaknesses. Ideally, what we would like to measure are the functional responses of predators to prey abundance directly. As a contribution towards this goal, we describe new technology that enables one to determine which predator killed which prey, at exactly what time, with improved research and management outcomes.
\end{abstract}

\section{Introduction}

For more than 60 years, rock-wallaby (RW) populations in many parts of Australia have been in decline; on 2 May 1973, in Western Australia (WA), Petrogale lateralis lateralis (RW) was declared an endangered species under the Western Australian Wildlife Conservation Act 1950, and its more recent distribution and status has been documented by Pearson and Kinnear (1997). Caughley (1994) defined the declining-population paradigm to suggest an organised approach to diagnose and rectify conservation problems involving continuing population declines. There are four competing hypotheses for the collapse of RW populations in WA. The limiting factor could be food, parasites and diseases, predators, or habitat loss. Beginning in 1979, the Wildlife Branch of the WA Department of Fisheries and Wildlife evaluated the competing hypotheses for RW declines, and decided that the key factor might be excessive predation by exotic predators, particularly the red fox. In 1982, they launched a predator-baiting experiment that was designed to test the hypothesis that red fox predation was limiting population growth of five endangered RW populations living on isolated rocky outcrops in the WA Wheatbelt. The red fox has long been considered an important limiting factor on Australian vertebrates (Hoy 1923; Wood Jones 1923-1925; Finlayson 1961; Christensen 1980; King et al. 1981; Copley 1983; Newsome et al. 1989; Friend 1990; Risbey et al. 2000; Short et al. 2002).
The first results from red fox baiting in WA were described in Kinnear et al. (1988b). This experiment represented the first attempt to test the hypothesis that fox depredation was limiting RW numbers in the WA Wheatbelt. Under fox control, the numbers at the treated sites were predicted to increase, until the carrying capacity was reached (or until another limiting factor intervened), whereas those at the untreated sites were expected to continue declining or remain very low. The censuses reported in 1984-86 were interpreted by Kinnear et al. (1988b) as evidence of a positive population response to fox control, but this was challenged by Hone (1994: pp. 93-96) on statistical grounds and by Caughley and Gunn (1996: p. 259) on methodological grounds. Four years later, the 1990 census and its analysis produced a more convincing outcome (Kinnear et al. 1998). Hone (1999) suggested additional tests by converting unbaited control sites to baited sites and by comparing the observed rate of increase with the maximum rate of increase if all predation were removed. These additional tests would help us determine whether red fox predation is the main threatening process for RWs or whether other processes might limit population increase.

Following the 1990 census (Kinnear et al. 1998), we had planned to continue the experiment as described; however, when we considered the precarious state of the control (unbaited) populations from the first experiments, we amended the 
experiment because, in the absence of fox poisoning, unbaited control populations were unstable and extinction prone-an observation supported from RW surveys in the arid zone of WA (Pearson 1992). These concerns prompted us after the 1990 census to amend the baiting protocol by extending fox control to the original three control sites (as recommended by Hone 1999), and to re-establish a population at one site that had gone extinct (Querekin).

The first part of this review reports on the predator-baiting trials since 1990 as a further test of the predation-limitation hypothesis, and with the benefit of hindsight, spanning a total of 25 years, we assess the contributions made by predator-baiting experiments to RW wildlife conservation in WA. The second part reviews the limitations of predator-baiting studies and, following Hone (1999), stresses the need to move forward. There is a pressing need to record predation events in real time to define precisely the functional responses of predators to their prey species. This information is critical for understanding predator-prey systems, and some of the questions that have surfaced during the past 25 years of baiting experiments in WA. We describe some enabling technology that holds the promise of recording in real time predator-prey interactions in the field.

\section{Materials and methods}

A map of the sites is illustrated in Fig. 1. Fox control consisted of laying 1080-poisoned baits at monthly intervals around the boundaries and inner tracks of Mount Caroline and Nangeen Hill at $100-\mathrm{m}$ intervals, and this was extended to the former control sites after the 1990 census. Baits containing 3.0-4.5 mg of 1080 were used.

For most trapping periods, 30 Bromilow 'soft' traps were situated wherever RW scats were evident (Kinnear et al. 1988a; during 2006-07, a mix of 40 Bromilow and Thomas soft traps were used). Trapping sessions were conducted during the dry season (December-April, principally February-March) when RW are most susceptible to live trapping. Traps were 'free baited' with apples for three or more days before the commencement of a trapping session. A trapping session consisted of setting traps before dusk, followed by a clearance of traps at 2200-2330 hours; the traps were reset and cleared again at first light ( $\approx 0600$ hours) next day. Captured RW were processed - e.g. tagged, weighed, sexed, females checked for pouched young (see Kinnear et al. 1988b). All captured animals were released at or near the capture site.

The logistics of trapping the five sites typically spanned 10-12 weeks and for this reason, the trapping protocol (typically two clearances per $24 \mathrm{~h}$ ) was implemented to maximise the trapping effort to take advantage of the optimal trapping period. The two clearances are treated (for statistical analysis) as two trap-nights whenever it was feasible to release the 2300 hours captures back into the population after a short time. However, as the populations increased and trap success increased accordingly, it was not always possible - in particular, in the case of first and second clearances - to process the animals quickly enough to release the catch back into the population for the following 0600 hours clearance, and so the traps were not reset on such occasions.

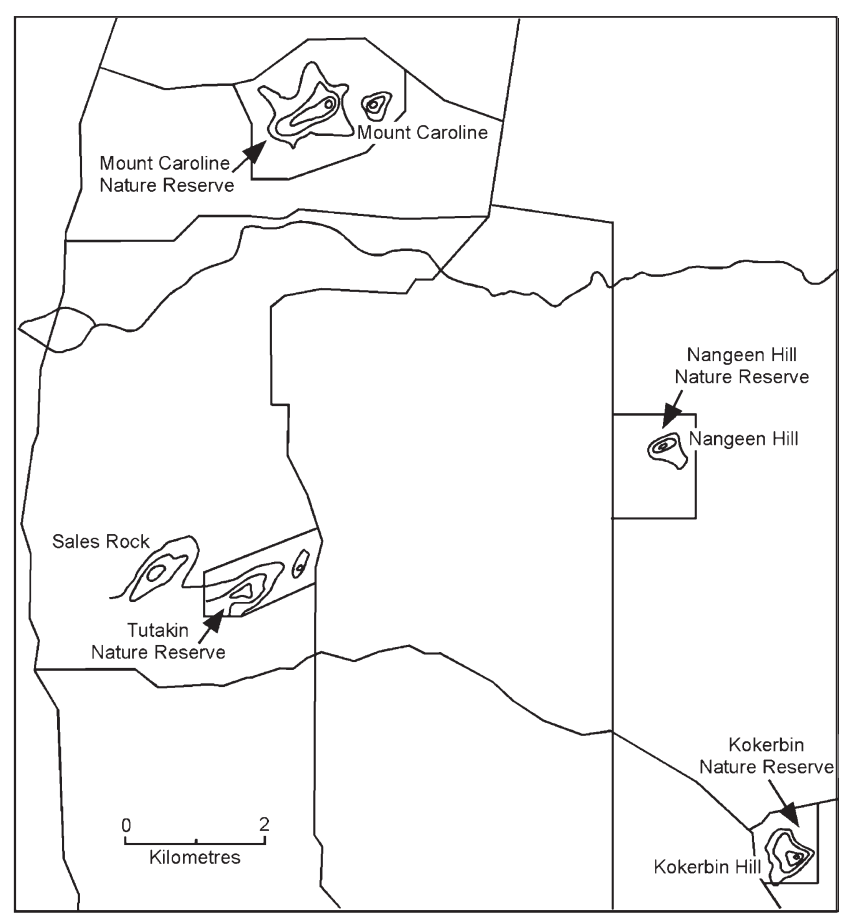

Fig. 1. The main experimental study area $\sim 20 \mathrm{~km}$ south of Kellerberrin, Western Australia $\left(31^{\circ} 50^{\prime} 08.6^{\prime \prime} \mathrm{S}, 117^{\circ} 40^{\prime} 58.5^{\prime \prime} \mathrm{E}\right)$. Once widespread in the Central Wheatbelt before the arrival of the fox, the rock-wallaby, Petrogale lateralis, managed to survive only at five sites (Mount Stirling not shown and not utilised because of access problems) and a sixth site $40 \mathrm{~km}$ to the SE (Querekin). Initially, two sites, Nangeen and Mount Caroline, were arbitrarily selected as experimental fox-control sites in 1982, and the remaining three were used as controls. It was not possible to select the sites randomly because in the case of Tutakin and Sales, baiting of either would have exercised fox control on the other. Kokerbin carried a population until 1960; it has since been recolonised (2002) by dispersal from Tutakin. All sites were baited from 1990.

A further modification of the trapping became necessary as the populations increased; in the cases of Mount Caroline and Nangeen Hill, it became necessary to trap these sites progressively in sections across the outcrops.

Population estimates before 1990 were estimated from the minimum number known to be alive (MNA). From 1990 onwards, we used Program CAPTURE and Program MARK to estimate population size and $95 \%$ confidence limits (Krebs 1999). The simple heterogeneity model $M_{\mathrm{h}}$ was the most likely model in almost all the data runs (tested by $\mathrm{AIC}_{\mathrm{c}}$ ), and we used this model for estimation. For all the populations sampled since 1990, the linear regression between MNA and CAPTURE estimates was CAPTURE $=-0.29+1.316$ MNA, with $r^{2}=0.99, n=17$. Thus, the use of the pre-1990 MNA estimates for population size introduces very little error because of the intensive livetrapping program.

\section{Results}

\section{Nangeen Hill}

This was one of the two classic sites discussed in detail in Kinnear et al. $(1988 b, 1998)$. The response of the RW population to sustained fox control is summarised in Fig. 2. Ten RWs were 


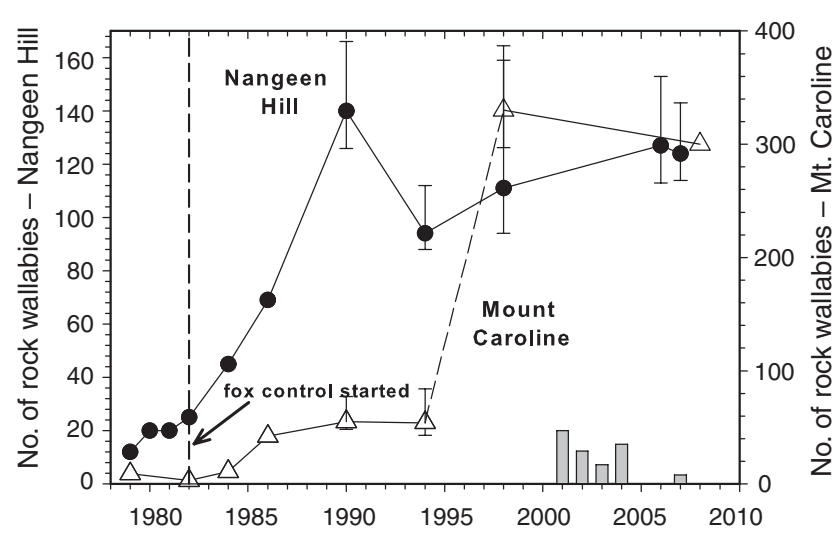

Fig. 2. Changes in rock-wallaby numbers on Nangeen Hill (1979-2007) and Mount Caroline (1979-98). Fox control was started in 1982 at these two sites. Estimates before 1990 are based on the number known to be alive. Error bars are $95 \%$ confidence limits. The Mount Caroline trapping area was enlarged in 1998 (see Fig. 3). The 2008 value for Mount Caroline was kindly provided by N. Willers (pers. comm.). The histogram shows the number of rock-wallabies removed from Mount Caroline for translocation after 2001.

removed from this site in 1990 to found a population at Querekin, and this removal may have been partly responsible for the population decline from 1990 to 1994 (see Appendix 1). Apart from the sustained population increase, there were marked changes in the behaviour of the wallabies and the spatial utilisation of the food and shelter resources on and around the outcrop. Prior to fox control, the population occupied a section of the outcrop that was characterised by a deeply fractured rock face that provided numerous crevices and small caves for shelter. After 8 years of fox control, the whole of the outcrop was utilised. Foraging range and behaviour were also affected. Before the implementation of fox control, the foraging range for RWs was limited more or less to the fractured site and to the meadow close to the base of the fractured section. As the population increased, wallabies were routinely observed feeding on the meadow $30-50 \mathrm{~m}$ from the rock face. These extensions of habitat use (realised niche expansion because of predator release) are commonplace responses by other RW populations, and other species subject to fox control such as the woylie Bettongia penicillata (Kinnear et al. 2002).

\section{Mount Caroline}

Mount Caroline is the second of the classic areas where fox control was instigated in 1982. Mount Caroline is a large smooth-faced (whaleback) granite monadnock, with scattered areas of fractured rock, and a low, fractured escarpment that dissects the outcrop (Fig. 3a, $b$ ). In the absence of fox control, and despite its larger size (371 ha), it supported fewer animals than did Nangeen Hill (176ha), a reflection of the quality of the refuge sites in providing protection from foxes. Baiting began on Mount Caroline in 1982 and the results are shown in Fig. 2. The behavioural changes were profound following baiting; virtually all of the fractured rock sites were eventually colonised, and by 1998, RW were discovered sheltering under nearby abandoned farm buildings and in brush piles (Fig. $3 b$ ).
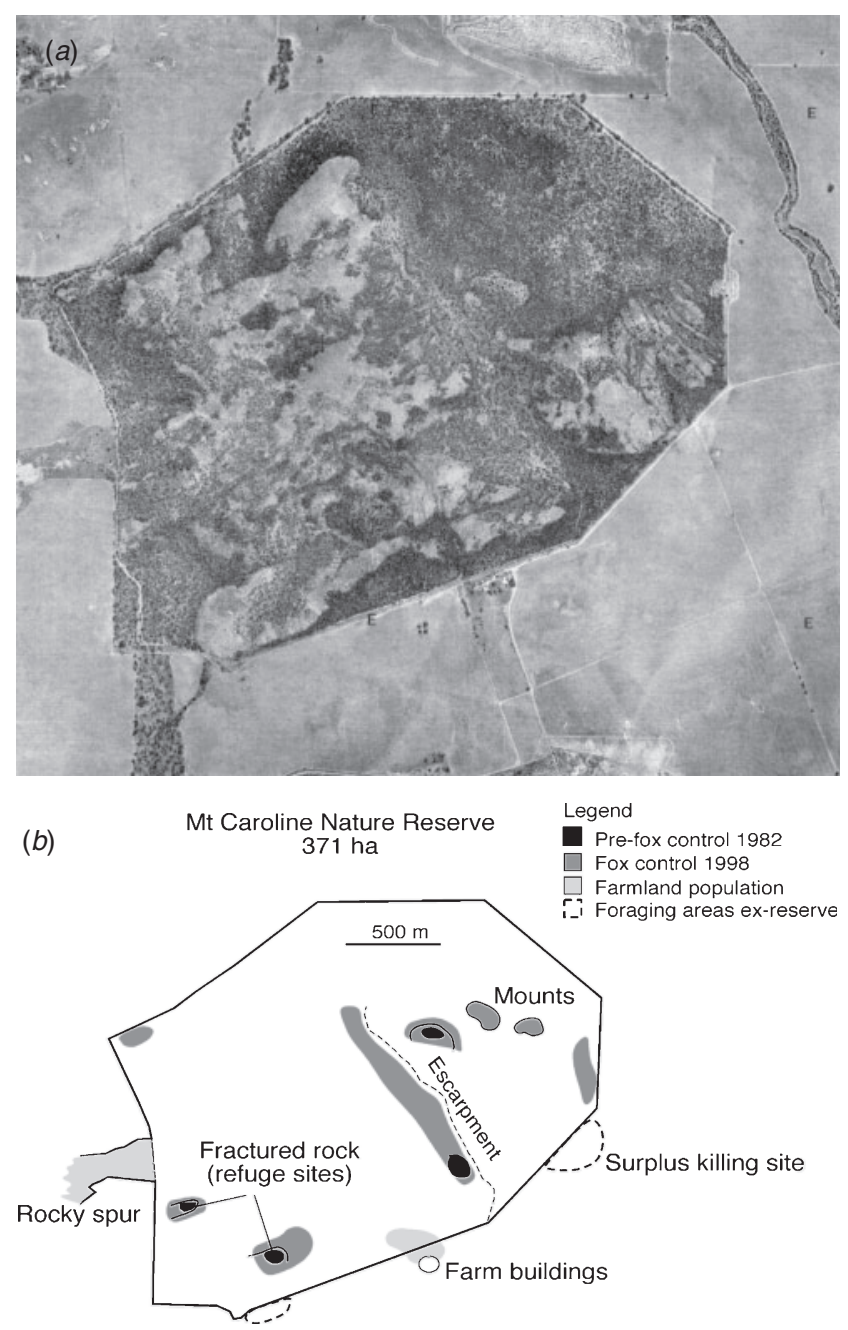

Fig. 3. (a) Aerial photograph of Mount Caroline Nature Reserve, showing the reserve boundaries surrounded by farmland. The monadnock is largely comprised of smooth rock with scattered areas of fractured rocky habitat depicted in the line drawing below. (b) A drawing showing the rock-wallaby shelter sites that served as predation refuges before fox control commenced in 1982 (small dark areas) and the expansion of shelter sites in use by 1998 under fox control. The rock-wallabies also colonised fractured areas of the rocky spur that extends out into a paddock, as well as some nearby abandoned farm buildings. Severe overgrazing has now occurred in the vicinity of the expanded shelter sites, causing the wallabies to invade some adjacent paddocks and damage crops, which necessitated the erection of a barrier fence. During an excursion into a paddock before the barrier was erected, a bout of surplus killing took place.

Groups were observed routinely leaving the rock to feed in the nearby crops, which, according to the farmers, caused significant economic damage and necessitated the construction of a barrier fence.

The trajectory of the population response to baiting was puzzling (Fig. 2). It increased from a baseline of less than 20 RWs to 43 animals after the first 4 years and stabilised at within a 43-50 range for the next 8 years (1986-1994). During the next 4 years, the population erupted to reach an estimated 330 animals (1998), a level that has been sustained (e.g. in $2009>300$ 
individuals; N. Willers, pers. comm.) during the last 10 years, despite the periodic removal of a total of 136 wallabies for translocation to other sites (Table 1). A further $20 \mathrm{RWs}$ were trapped on or near a rocky spur of Mount Caroline that projects out into an adjacent paddock (Fig. 3a). This is another example of where fox control, when limited to a defined area, can provide some protection outside of the targeted area (see also Kinnear et al. 2002; e.g. 'Friend's baited area', Dryandra site). It is noteworthy that the 136 removals (Table 1) taken over 7 years for translocation purposes, an average 'management predation rate' of 19 animals per year, did not cause a long-term population decline (see Appendix 1).

The question as to what caused the Mount Caroline population to stabilise within the 40-50 range and then erupt to $>300$ remains a puzzle. The most likely cause was inadequate sampling before 1998. For an 8-year period, the population appeared to stabilise near 50 and this was assumed to be carrying capacity. What we failed to recognise was the need to trap a wider area of the rock because the predator-release effect on habitat use went unnoticed. By 1998, this expansion of habitat use was obvious, and the sampling area was accordingly enlarged (Fig. $3 b$ ).

\section{Sales' Rock}

Sales' Rock was initially a control site for the 1982 experiment and no fox management was carried out from 1979 to 1990 on this area. Sales' Rock is a 'whaleback'-shaped granite monadnock, with a deeply fractured area comparable to Nangeen Hill at one end, and a smaller area at the opposite end of the outcrop. As a control site, the population was notable for its instability (Fig. 4). It increased during the initial phase of the experiment (1982-1986), which confounded the early interpretations (Kinnear et al. 1988b); however, the 1990 census revealed that it had crashed (Kinnear et al. 1998). Following the implementation of fox control in 1990, it has responded in a typical manner, showing a steady increase (Fig. 4).

\section{Querekin}

The Querekin site (Fig. 5; 40 km to the south-east) is unique in that it is the only RW site with a historical record. It is worth

Table 1. By 2001 the Mount Caroline and Querekin populations achieved pest status and were causing economic damage to nearby farm properties

Accordingly, in an effort to alleviate the damage, both populations were periodically trapped and the rock-wallabies (RW) were translocated to sites where they formerly occurred (see text)

\begin{tabular}{lcc}
\hline Year & $\begin{array}{c}\text { Number RW removed } \\
\text { Mount Caroline }\end{array}$ & Querekin \\
\hline 2001 & 47 & 0 \\
2002 & 29 & 21 \\
2003 & 17 & 36 \\
2004 & 35 & 10 \\
2005 & 0 & 15 \\
2006 & 0 & 0 \\
2007 & 8 & 11 \\
2008 & 0 & 5 \\
Total & 136 & 98 \\
\hline
\end{tabular}

discussing because it shows that RWs were not troubled by the presence of humans nor by the massive changes to the landscape brought on by intensive agricultural clearing in the Wheatbelt of WA. The following account recorded by J.E. K. and M. Onus was from a 1979 interview with Nigel Beaton (then retired), a first generation family member who was raised on the property.

The outcrop consists largely of smooth rock, with a fractured area at one end and small breakaway at the opposite end. It was first settled in 1908 and the homestead and farm buildings were built in close proximity to the outcrop (Fig. 5). Following settlement, the RW population continued to thrive; at night they could be heard hopping around the homestead veranda and, given the opportunity, they would climb up a ladder and feed on hay stored in a loft. During the harvest, RWs would leap on to wagons carrying bags of wheat and feed on the spilled grain. $\mathrm{Mr}$ Beaton recalled that on one occasion more than 100 wallabies were counted on the rock.

After the arrival of the red fox in the late 1920s, changes occurred. RWs were known from other outcrops in the surrounding countryside, but these populations disappeared after the arrival of foxes, as did bilbies (Macrotis lagotis). Our inspection of these sites (Mount Shackleton, Mokenby) revealed that they were rather insignificant outcrops, offering little security in the presence of red foxes. In 1979, the then owners (Langdon) appealed for advice after sightings declined from 16 to 7 animals. A fox den had been discovered at the base of the outcrop and a fox was poisoned; thereafter, the sightings stabilised at seven. We excavated the den and RW remains were found; we then offered to bait the site, but this was declined. Subsequently, the property was sold in 1983 and remained vacant for 6 months. One RW was trapped in 1986 and none in 1990. Inspection of the site in 1990 failed to detect any fresh signs and the population was declared to be extinct.

Following these results and at the behest of the new owners, 10 RWs were translocated in 1990 from Nangeen Hill and the site has been baited ever since. A census was performed in December 1997 and 2007 (Fig. 4).

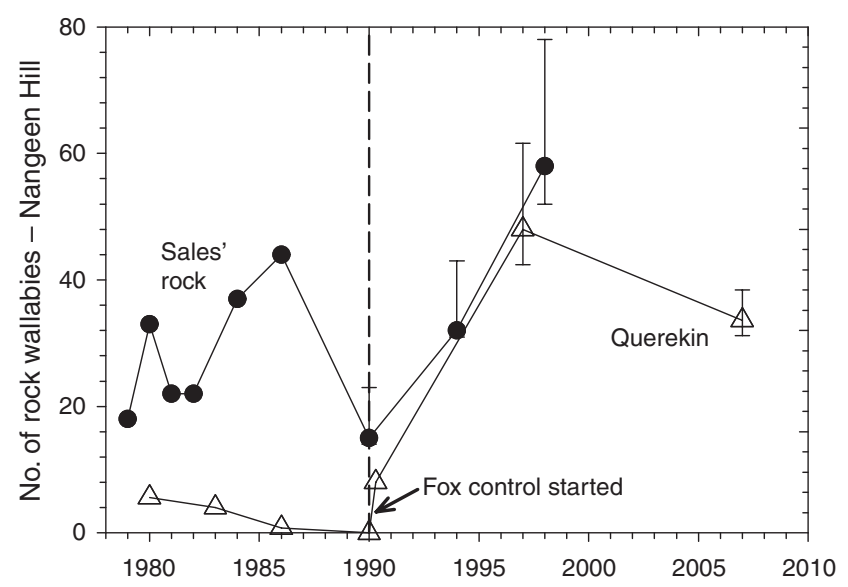

Fig. 4. Changes in rock-wallaby numbers at two sites during the 1980s when there was no fox baiting, and after 1990 when baiting was started. The Querekin site went extinct in early 1990 and 10 wallabies were introduced later that year. Subsequently, wallabies reached pest status and in an effort to reduce the population, 98 individuals were removed during the period 2002-07 (Table 1) for translocation purposes. In 2007, 36 were trapped. 


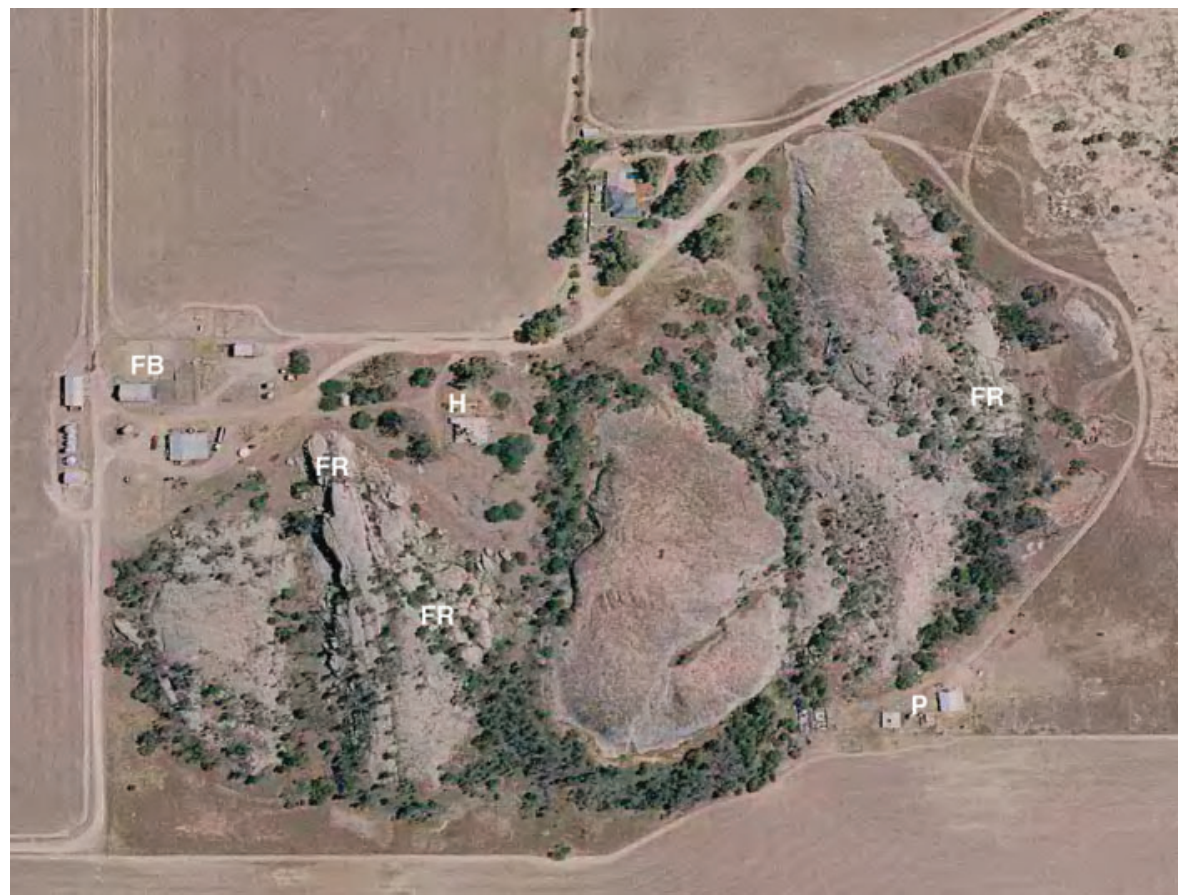

Fig. 5. The Querekin site. The site was settled by the Beaton family in 1908 who built their homestead and farm buildings next to the rock. The rock-wallaby colony continued to flourish for 20 years despite major changes to the surrounding landscape, only to decline following the arrival of the fox. Subsequent owners practiced fox and cat control opportunistically by shooting and poisoning; however, the colony became extinct by 1990. Rock-wallabies were introduced under fox control and by 2002 had reached pest status. $\mathrm{H}$, the original homestead; FR, fractured rock sites used as shelter; FB, farm buildings housing machinery colonised by RW under baiting; P, piggery, frequented by RW foraging for grain spillage around silos.

By 2002, the population had achieved pest status because of the propensity of the RW to climb all over harvesting machinery in search of wheat residues; this activity contaminated the machinery with droppings and subsequently the harvested grain. In an effort to reduce the population, $98 \mathrm{RWs}$ were removed from Querekin during the period 2002-08 and used for translocations (Table 1). The site was trapped in 2007 and 36 wallabies were captured. It is not known whether the removals were the sole cause of the decline from pest status levels, because the site was overgrazed and it was visually apparent that the wallabies had lost some condition.

\section{Tutakin}

Tutakin was initially a control site for the 1982 experiment, like nearby Sales' Rock, and no fox control was carried out from 1979 to 1990 . Tutakin is a smooth-faced low monadnock surrounded by thick vegetation at the base; it is largely intact except for a small breakaway and meadow at the base that supported $<10 \mathrm{RWs}$ in the absence of fox control. Under fox control, the population has increased steadily (Table 2). The population increase may have triggered dispersal because RWs were discovered on Kokerbin Rock (2002, Fig. 1), and DNA microsatellite loci analyses revealed that the founders were sourced from Tutakin, $\sim 9 \mathrm{~km}$ away (M. D. L. Eldridge, P. Orell and C. Groom, unpubl. data). Unfortunately, we do not have any population estimates for Tutakin since 1998.
Table 2. From 1983 to 1990, the Tutakin MNA statistic was stable at six or seven wallabies

Fox baiting commenced after the 1990 census. A dispersal event in 2002 was linked to the site (see text); CL, confidence limit

\begin{tabular}{lcccc}
\hline Year & MNA & $\begin{array}{c}\text { Population } \\
\text { estimate }\end{array}$ & $\begin{array}{r}\text { Lower } \\
95 \% \text { CL }\end{array}$ & $\begin{array}{r}\text { Upper } \\
95 \% \text { CL }\end{array}$ \\
\hline 1990 & 7 & 7 & 7 & 17 \\
1994 & 15 & 18 & 16 & 32 \\
1998 & 20 & 34 & 26 & 57 \\
\hline
\end{tabular}

\section{The Gardner site: a population founded by dispersal}

In 1995, Bevan Gardner, the owner of a farming property (since 1978) approximately $8 \mathrm{~km}$ north of Mount Caroline, reported the sighting of a RW for the first time ever on a small outcrop near the farm residence. A 1998 census recorded six individuals; DNA microsatellite analyses implied that the population was founded by a single female with a male pouched young from Mount Caroline (Eldridge et al. 2001). This population persisted under fox control until recently; however, a change in circumstances led to the cancellation of baiting, and the colony is now extinct.

\section{Discussion}

The data reported here for the five sites studied are consistent with the predation-limitation hypothesis (Kinnear et al. 1988b, 1998) 
and identify red fox predation as a major limiting factor to RW populations in the Wheatbelt of WA. To manage these populations effectively, we must consider what other factors might limit RW populations once predation limitation is reduced, and what further details we need to understand about the role of predators in this ecosystem.

\section{The role of rocky habitat}

The fragmented habitat of RWs provides two important services, namely the provision of thermal and predation refuges. The former allow RWs to avoid extremes of cold and heat, which saves energy and avoids the need to drink or expend body water for thermoregulation. In physiological terms, rock piles enable RWs to exist for much of their life span within their thermoneutral zone. If free water or succulent green food is available as agricultural subsidies, RWs are able to reach pest status by sheltering in brush piles and abandoned farm buildings (Fig. $3 b$ ) away from rocky habitats.

Fragmented rocky sites also serve as predation refuges, especially since the arrival of the red fox. Ever since then, security in the form of deeply fragmented sites has become paramount. Rock piles have thermal refuges offering varying levels of security, and in the presence of the fox, only those sites providing a high level of security with food nearby were able to support colonies. Inspections of sites where RWs were known to have existed historically (but now extinct) were invariably judged by us to be lacking in this form of security, i.e. lacking deeply fractured sections.

The effect of fox control can be summarised simply as follows: baiting reset the carrying capacity of the rocks to a higher level because security was no longer a limiting factor; however, this has since led to unforeseen consequences, including severe overgrazing on Mount Caroline and Nangeen Hill where weeds have now invaded (C. Pentland and R. Inglis, unpubl. data).

\section{Managing the overgrazing problem}

Food supplies are clearly the second-most important limiting factor for RWs, although this has been very little studied. Resetting the carrying capacity of the fragmented rocky sites by baiting enabled the wallabies to reoccupy less secure thermal refuges; what it did not, and could not do, was to reset the available food supply. There are two reasons for this. The first stems from the massive clearing of the landscape where, in many cases, paddocks were cleared to the base of the rock (Figs $3 a, 5$ ), thus depriving the colonies of much of their original food supply. One solution to increasing the available food supply would be to purchase land surrounding important outcrops and restore the natural vegetation; however, the benefits of this step would be dependent on intensifying the level and extent of fox control.

The second reason is based on direct observations that confirm that the current level of fox control is not absolute in that it does not prevent foxes from invading a baited area. Intensive observational studies with night-vision equipment on Nangeen Hill by one of us (C. P.) has recorded the reactions of foraging wallabies to invading foxes that occasionally make their appearance. The appearance of a fox is recognised as a threat by RWs, as they flee en masse to the rock and do not subsequently resume foraging. These observations conform to Brown and Kotler's (2007) concept of predator-driven systems, namely those that are mortality-driven (N-driven) and fear-driven ( $\mu$-driven). Thus, even the mere presence of foxes ( $\mu$-driven system) can be detrimental, because prowling foxes can significantly affect foraging time and foraging range of the wallabies, which leads in turn to overgrazing of the sites and the likelihood of population collapse.

One possible solution would be to extend fox control over a wide area, thus creating a buffer zone surrounding the outcrops (see Thomson et al. 2000). An effective buffer would reduce the invasion rate to near zero, thus creating a sense of security among the RWs, which would then promote wider foraging ranges. More effective fox control is essential because the risk to RWs that do venture away from shelter is real; an example occurred on Mount Caroline when RWs started to routinely feed in a nearby crop (Fig. 3b); eventually, an episode of surplus killing occurred (Short et al. 2002).

\section{Predator-baiting studies: what has been learned?}

The cause of the unprecedented catastrophic decline of Australia's continental mammal fauna (Burbidge and McKenzie 1989; Woinarski and Braithwaite 1990) has been anecdotally linked to the red fox by observers, museum workers and naturalists during the past century; however, this link has been opposed by the conventional wisdom of the day regarding the perceived role of predators in Australian ecosystems (Kinnear et al. 1998, 2002). Although it is possible to question the outcome of one or two field experiments, a sufficient number of replications have now been performed to convince sceptics that fox predation is indeed the premier threatening process for RWs and many other mammals in Australia. The positive results from fox baiting have stood the test of time for over 25 years, and much has been learned. We summarise here the insights that have been obtained during the last three decades by many workers (see Kinnear et al. 1998: table 10; Start and Mawson 2004, a review of WA Western Shield).

A fundamental limitation of fox-baiting experiments is that we do not know the absolute abundance of the foxes before and after the poison-baiting episode. This basic problem has been well recognised in predation reviews (Robley et al. 2004).

It has been shown repeatedly that the application of 1080 baits kills foxes over wide areas of the Australian landscape (e.g. Banks et al. 1998; Kinnear et al. 1988b, 2002; Thomson and Algar 2000; Thomson et al. 2000; Start and Mawson 2004). We infer that this reduction in fox numbers is the cause of significant population increases that have occurred in 11 marsupial species, often from extremely low population levels that were barely detectable (Kinnear et al. 2002). Fox baiting has also made possible the successful translocations of endangered fauna to sites where they formerly occurred. Fox baiting has also produced some problems for wildlife managers. In some cases, rare and endangered populations have been transformed into local pests; e.g. RWs at Mount Caroline and Querekin, tammar wallabies at Tutanning Nature Reserve (P. Orell, unpubl. data).

The contrary view is that fox baiting does not reduce fox numbers. Greentree et al. (2000) reported no clear evidence of reduced fox numbers after 1080 baiting in south-eastern Australia, even though they found many dead foxes after 
baiting and lamb mortality owing to fox predation was reduced on the baited areas. They suggested that the lack of a significant reduction in their index of fox density (spotlight counts) might be caused by rapid dispersal of foxes into the baited areas.

How fast are baited areas recolonised by foxes? Early on it was apparent that dispersal can be very rapid, especially on small reserves in an agricultural landscape. This was evident from exploratory trials before 1982, when foxes were eradicated (as judged by the absence of fox footprints on graded firebreaks and tracks) by baiting on Nangeen Hill. Reinvasion was apparent in a matter of days in some cases, and invariably so within a month, a finding that led to the adoption of the monthly baiting protocol by Western Shield.

Baiting works because most foxes do not survive for long and population turnover is rapid (Kinnear et al. 1988b: fig. 3). For small RW populations (20-30 animals), absolute fox control would appear to be mandatory initially; however, as the RW population increases, a finite (density-dependent) level of fox predation becomes tolerable (see Appendix 1 for more details). The other side of the coin is that foxes can be efficient managers of potential marsupial pests. Where foxes are absent, as in Tasmania (previously fox-free) and Kangaroo Island, mediumsized marsupials have proven to be pests (Kinnear et al. 2002; P. Orell, unpubl. data; Figs $3 b, 5$ ) It therefore seems likely that Australian mainland communities have been spared the task of managing potential marsupial pests because an unknown ally, the fox, has been quietly at work; indeed, so comprehensively, it should be recognised as a biocontrol agent (Kinnear et al. 2002).

Fox control is associated with the dispersal of RWs, which appears to be density dependent and therefore associated with the baiting history. It is noteworthy that despite the close proximity of Tutakin and Sales (two control sites, Fig. 1), DNA microsatellite analyses found that these populations are distinct (Eldridge et al. 2001, 2004). The distribution of RW populations, both past and present (Pearson and Kinnear 1997) implies that it is a species with a classic metapopulation structure maintained by dispersal, and two cases were observed during the present study after population recoveries. The first was the Gardner's population; a second dispersal was detected in 2002 on Kokerbin Rock, which is known to have supported RWs until 1960 (Fig. 1). DNA tests traced the source population to Tutakin (M. D. L. Eldridge, P. Orell and C. Groom, unpubl. data).

Baiting studies have shown that fox predation has distorted ecological perceptions about the preferred habitat requirements of many species. Persistence in the absence of fox control is associated with habitats that serve as refugia (e.g. deeply fractured rock, dense cover, arboreal habitats). Under fox baiting, threatened species recolonise and exploit habitats outside of refugia, e.g. the occupation by $\mathrm{RW}$ of vacant rocky sites as observed on Nangeen, Mount Caroline, and even farm buildings and brush piles (Mount Caroline, Querekin).

We do not recommend, however, that managers promote and rely on refugia alone to conserve species. Refugia should be recognised as survival niches, but subject to the caveat that they are not necessarily stable in the absence of predator control. Furthermore, the habitat of populations persisting at unbaited sites should automatically be assumed to be refuges and therefore researched and managed accordingly until shown otherwise.
Summing up the benefits achieved by reducing a predator population by the simple process of laying poison baits, we believe that its greatest legacy will be the following: it has alerted the conservation community about the magnitude of the exotic-predator threat to Australia's wildlife. This awareness has produced dividends as it has triggered an early response to the unfortunate release of foxes into Tasmania, which hopefully will result in their eradication.

\section{Measuring what was immeasurable}

Fox-baiting experiments in WA have given credence to the belief that red foxes in Australia over-exploit their marsupial prey to the extent that coexistence is unstable or impossible. Despite such findings, the baiting design is wanting in many respects because it is a black-box research tool, and as such, it tends to produce more questions than answers. Basically, the input into the box is 'lay baits', and the output is 'more prey'. Critical questions remain unanswered principally because exotic predatormarsupial relationships are cryptic predator - prey systems that remain immeasurable without access to appropriate remotesensing electronic aids (Molsher et al. 1999; Risbey et al. 2000). Recent developments have made this goal feasible, and we conclude the present paper by describing some enabling technology that is now available for field trials.

To move forward, there is a pressing need to obtain data about the circumstances that surround individual predation events. More specifically, we need to know

(1) who is doing the killing;

(2) who is being killed; and

(3) how often do kills take place and exactly when?

Ideally, it would be desirable to collect such data over all prey densities, because this information would describe a predator's functional response - the kill rate of the predator at any prey density (Holling 1965). The first two questions provide vital qualitative information; the third provides both qualitative and quantitative data. The benefits of knowing the answers to these questions about predation events are as follows:

(1) Who is doing the killing? Currently the specific identity of any particular predator is generally unknown; indeed, even the species of predator may be unknown. Are the culprits foxes or feral cats (Felis catus, Spencer 1991) or dingos (Canis lupus dingo), or native predators such as wedge-tailed eagles (Aquila audax)? Is every putative predator a killer, or are there certain individuals who do most of the killing? This is an absolutely critical question often asked, but for which there are no data at all. Is there a gender bias in predation? Do predators, such as dingos, kill other predators such as foxes and cats, and does the fauna benefit? Does mesopredator release follow the removal of a top predator and if so, what are the consequences (Johnson et al. 2007; Rayner et al. 2007; Prugh et al. 2009)?

(2) Who is being killed? There has been a general belief among students of predation that the weak and the sick are predisposed to become victims. However, the data on this question are equivocal (Temple 1987; Wirsing et al. 2002). Are the victims biased in favour of certain age classes or is the 
killing random? Is there a gender bias? Are females laden with large pouched young more vulnerable?

(3) How often do individual predators kill and when? Is there a diurnal pattern or a seasonal effect? Is fox predation episodic or intermittent as suggested by Sales' Rock data? Likewise, are there situations that lead to bouts of predation that involve surplus killing (Oksanen et al. 1985; Short et al. 2002)? Do predators switch prey according to foraging theory, e.g. after rabbit population crashes? Are there predictable patterns of predation that can help managers protect threatened species more effectively?

The key to collecting data about the above list of questions is recording contacts between a predator and prey. We have now developed a system capable of recording such contacts along with the relevant details for each encounter, and we now briefly describe this new technology (Fig. 6).

The tracking system comprises the following three devices:

(1) a prey collar, when triggered, emits a unique ID number, and if the contact results in a kill, the collar signal will signify that a mortality event has occurred;

(2) a predator collar, which triggers a prey collar and stores the prey's ID number, along with the date and time, thus recording a contact from which a kill can be ascertained; and

(3) A field data collection unit that remotely interrogates the predator collar for contacts and downloads data for analysis.

Some of the details of the tracking system and how it can be used are as follows:

(1) predator collars and prey collars are attached to animals of interest;
(2) predator and prey collars are programmed with variable parameters such as transmission power, polling interval and whether to beacon after mortality before they are deployed;

(3) the prey collar checks and records the mortality status of the host animal by means of an activity switch or a temperature sensor on the collar; if the activity or temperature switch is activated because the host animal has died, the prey collar enters mortality mode where it will emit beacon signals that signify this, thus enabling the researcher to recover the corpse and retrieve the collar;

(4) the predator collar on contact triggers a prey collar when positioned closer than a fixed distance, depending on the predator-prey system;

(5) when the prey collar is so triggered, it broadcasts its unique identification number to the predator collar which is recorded and stored along with the date and time;

(6) if the contact between predator and prey results in a kill, then the prey collar will enter mortality mode and broadcast its position; if the prey escapes, the contact is nevertheless recorded and stored; this feature enables the researcher to distinguish unsuccessful contacts from kills;

(7) the predator collar also regularly attempts to establish communication with a field data-collection unit (a laptop or PDA) which enables the researcher to download the stored information from the predator collar remotely;

(8) the system (patent pending) can be integrated with existing telemetry systems, including GPS systems.

Radio-collars that will achieve these goals are already available; further information can be obtained from coauthors
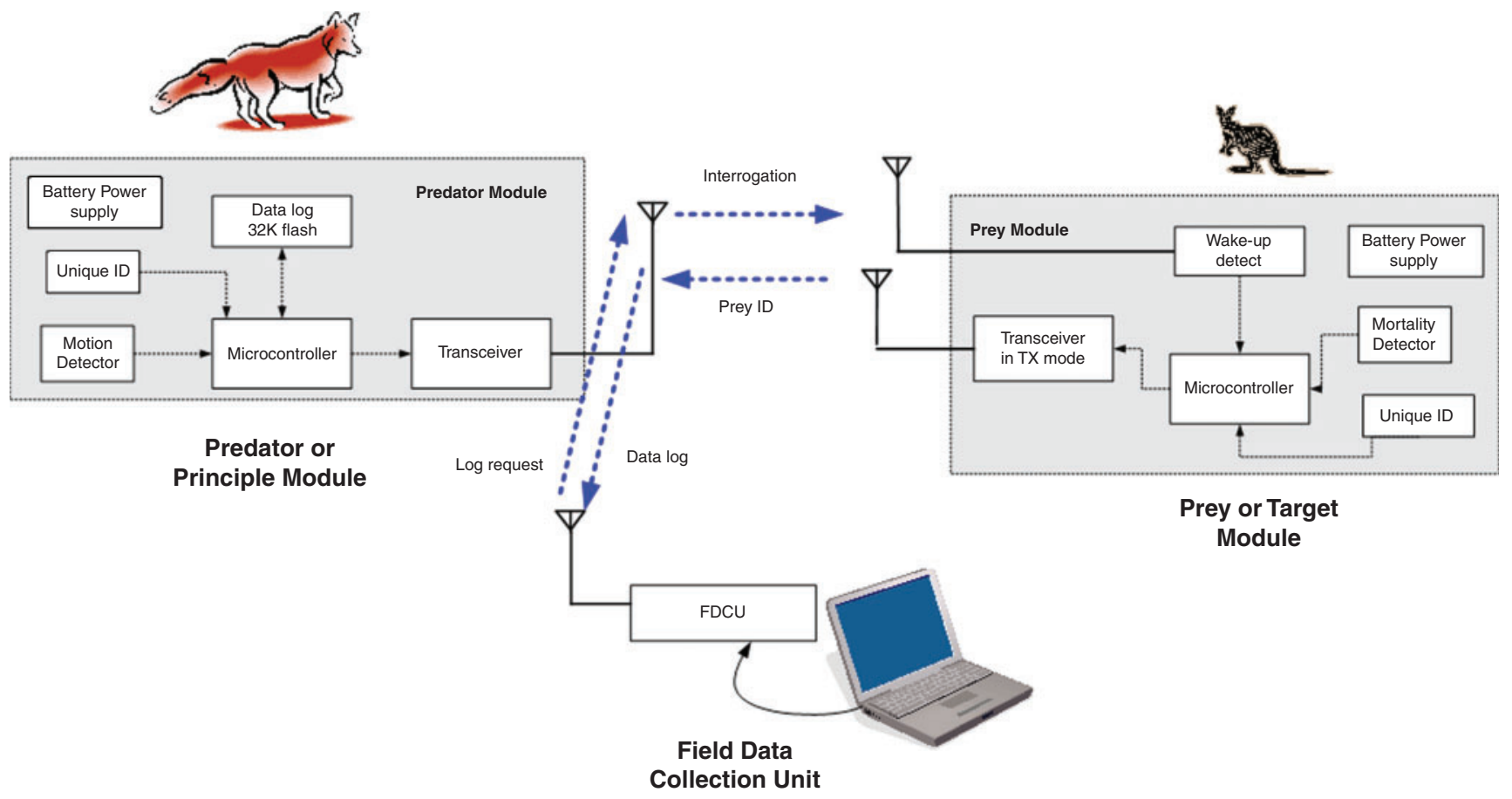

Fig. 6. A contact telemetry system designed to (1) detect encounters between an individual predator and a prey animal, (2) store relevant information about the encounter and (3) remotely retrieve such information. 
C. Holme and R. Karvinen of Edith Cowan University in WA (christopher.holme@ecu.edu.au, or r.karvinen@ecu.edu.au).

\section{Concluding remarks}

The role of fox predation as a threatening process affecting the survival of many mammal species in Australia is now well established, although there is much we do not know (Robley et al.2004). Studying cryptic predator-prey systems in the field is a daunting task. The understanding we now have can be increased and enriched by new technical developments. Just as the arrival of radio-telemetry and DNA methods have helped us achieve a deeper understanding of species interactions, we are confident that the emerging improvements in radio-telemetry technology described here will signal another round of major advances in analysing vertebrate predator-prey dynamics in food webs.

\section{Acknowledgements}

A project of this nature and longevity (1978-2007) situated in the Western Australian Wheatbelt would not have been possible without the cooperation and goodwill of the farming families whose properties contained or abutted the rock-wallaby sites. We once again thank the McDonald, Canova, Sales, Hammond and Crooke families for allowing unfettered access to their properties, while tolerating our coming and goings often at the oddest of hours. We also acknowledge the major contributions of Senior Technical Officer Michael Onus, a founding member of the project, Rowan Inglis, and the volunteers who assisted with the trapping during 2006/2007. We are grateful to A. Kinnear for her many contributions. The interest and collaboration of Mark Eldridge is much appreciated. The ethics approval numbers granted by the WA Department of Environment and Conservation Animal Ethics Committee (formerly CALM) are: CALM AEC 2001/08, CALM AEC 2003/27, CALM AEC 2003/30, and DEC AEC 2006/36. The Edith Cowan AEC approval code for C. Pentland's research is 03-A18.

This paper is dedicated to the memory of Howard Robinson, in recognition of his contributions to rock-wallaby conservation.

\section{References}

Banks, P. B., Dickman, C. R., and Newsome, A. E. (1998). Ecological costs of feral predator control: foxes and rabbits. Journal of Wildlife Management 62, 766-772. doi: $10.2307 / 3802353$

Brown, J. S., and Kotler, B. P. (2007). Foraging and the ecology of fear. In 'Foraging: Behaviour and Ecology'. (Eds D. W. Stephens, J. S. Brown and R. C. Ydenberg.) pp. 437-448. (The University of Chicago Press: Chicago, IL.)

Burbidge, A. A., and McKenzie, N. L. (1989). Patterns in the modern decline of Western Australia's vertebrate fauna: causes and conservation implications. Biological Conservation 50, 143-198. doi:10.1016/00063207(89)90009-8

Caughley, G. (1994). Directions in conservation biology. Journal of Animal Ecology 63, 215-244. doi:10.2307/5542

Caughley, G., and Gunn, P. (1996). 'Conservation Biology in Theory and Practice.' (Blackwell Science: Cambridge, MA.)

Christensen, P. E. S. (1980). A sad day for the fauna. Forest Focus 23, 3-12.

Copley, P. B. (1983). Studies on the yellow-footed rock-wallaby, Petrogale xanthopus Gray (Marsupialia: Macropodidae). I. Distribution in South Australia. Australian Wildlife Research 10, 47-61. doi:10.1071/ WR9830047

Eldridge, M. D. B., Kinnear, J. E., and Onus, M. L. (2001). Source population of dispersing rock-wallabies (Petrogale lateralis) identified by assignment tests on multilocus genotypic data. Molecular Ecology 10, 2867-2876.
Eldridge, M. D. B., Kinnear, J. E., Zenger, K. R., McKenzie, L. M., and Spencer, P. B. S. (2004). Genetic diversity in remnant and 'pristine' island populations of three endemic Australian macropods (Marsupalia): Macropus eugenii, Lagorchestes hirsutus and Petrogale lateralis. Conservation Genetics 5, 325-338. doi:10.1023/B:COGE.0000031148. 59923.aa

Finlayson, H. H. (1961). On Central Australian mammals. Part IV. Records of the South Australian Museum 14, 141-191.

Friend, J. A. (1990). The numbat Myrmecobious fasciata, Myrmecobidae: history of decline and potential for recovery. Proceedings of the Ecological Society of Australia 16, 369-377.

Greentree, C., Saunders, G., Mcleod, L., and Hone, J. (2000). Lamb predation and fox control in south-eastern Australia. Journal of Applied Ecology 37, 935-943. doi:10.1046/j.1365-2664.2000.00530.x

Holling, C. S. (1965). The functional response of predators to prey density and its role in mimicry and population regulation. Memoirs of the Entomological Society of Canada 45, 1-60.

Hone, J. (1994). 'Analysis of Vertebrate Pest Control.' (Cambridge University Press: Cambridge, UK.)

Hone, J. (1999). Fox control and rock-wallaby population dynamics assumptions and hypotheses. Wildlife Research 26, 671-673. doi:10.1071/WR98083

Hoy, C. M. (1923). The present status of the Australian mammal fauna. Journal of Mammalogy 4, 164-166. doi:10.2307/1373565

Johnson, C. N., Isaac, J. L., and Fisher, D. O. (2007). Rarity of a top predator triggers continent-wide collapse of mammal prey: dingoes and marsupials in Australia. Proceedings of the Royal Society of London. Series B. Biological Sciences 274, 341-346. doi:10.1098/rspb.2006. 3711

King, D. R., Oliver, A. J., and Mead, R. J. (1981). Bettongia and fluoroacetate: a role for fauna management. Australian Wildlife Research 8, 529-536. doi:10.1071/WR9810529

Kinnear, J. E., Bromilow, R. N., Onus, M. L., and Sokolowski, R. E. (1988a). The Bromilow Trap: a new risk-free soft trap suitable for small to medium-sized macropodids. Australian Wildlife Research 15, 235-237. doi:10.1071/WR9880235

Kinnear, J. E., Onus, M. L., and Bromilow, R. N. (1988b). Fox control and rock-wallaby population dynamics. Australian Wildlife Research 15, 435-450. doi:10.1071/WR9880435

Kinnear, J. E., Onus, M. L., and Sumner, N. R. (1998). Fox control and rock-wallaby population dynamics. II. An update. Wildlife Research 25, 81-88. doi:10.1071/WR96072

Kinnear, J. E., Sumner, N. R., and Onus, M. L. (2002). The red fox in Australia - an exotic predator turned biocontrol agent. Biological Conservation 108, 335-359. doi:10.1016/S0006-3207(02)00116-7

Krebs, C. J. (1999). 'Ecological Methodology.' 2nd edn. (Addison-Wesley Longman: Menlo Park, CA.)

Molsher, R., Newsome, A., and Dickman, C. (1999). Feeding ecology and population dynamics of the feral cat (Felis catus) in relation to the availability of prey in central-eastern New South Wales. Wildlife Research 26, 593-607. doi:10.1071/WR98058

Newsome, A. E., Parer, I., and Catling, P. C. (1989). Prolonged prey suppression by carnivores - predator-removal experiments. Oecologia 78, 458-467. doi:10.1007/BF00378734

Oksanen, T., Oksanen, L., and Fretwell, S. D. (1985). Surplus killing in the hunting strategy of small predators. American Naturalist 126, 328-346. doi:10.1086/284420

Pearson, D. J. (1992). Past and present distribution and abundance of the black-footed rock-wallaby in the Warburton region of Western Australia. Wildlife Research 19, 605-622. doi:10.1071/WR9920605

Pearson, D. J., and Kinnear, J. E. (1997). A review of the distribution, status and conservation of rock-wallabies in Western Australia. Australian Mammalogy 19, 137-152. 
Prugh, L. R., Stoner, C. J., Epps, C. W., Bean, W. T., Ripple, W. J., Laliberte, A. S., and Brashares, J. S. (2009). The rise of the mesopredator. Bioscience 59, 779-791. doi:10.1525/bio.2009.59.9.9

Rayner, M. J., Hauber, M. E., Imber, M. J., Stamp, R. K., and Clout, M. N. (2007). Spatial heterogeneity of mesopredator release within an oceanic island system. Proceedings of the National Academy of Sciences, USA 104, 20862-20865. doi:10.1073/pnas.0707414105

Risbey, D. A., Calver, M. C., Short, J., Bradley, J. S., and Wright, I. W. (2000). The impact of cats and foxes on the small vertebrate fauna of Heirisson Prong, Western Australia. II. A field experiment. Wildlife Research 27, 223-235. doi:10.1071/WR98092

Robley, A., Reddiex, B., Arthur, T., Pech, R., and Forsyth, D. M. (2004). Interactions between feral cats, foxes, native carnivores, and rabbits in Australia. Arthur Rylah Institute for Environmental Research, Department of Sustainability and Environment, Melbourne.

Short, J., Kinnear, J. E., and Robley, A. (2002). Surplus killing by introduced predators in Australia - evidence for ineffective anti-predator adaptations in native prey species? Biological Conservation 103, 283-301. doi:10.1016/S0006-3207(01)00139-2

Skalski, J. R., Ryding, K. E., and Millspaugh, J. J. (2005). 'Wildlife Demography: Analysis of Sex, Age, and Count Data.' (Elsevier Academic Press: Amsterdam.)

Spencer, P. B. S. (1991). Evidence of predation by a feral cat, Felis catus (Carnivora: Felidae) on an isolated rock-wallaby colony in tropical Queensland. Australian Mammalogy 14, 143-144.
Start, T., and Mawson, P. (Eds) (2004). A review of Western Shield. Conservation Science Western Australia 5, 1-258.

Temple, S. A. (1987). Do predators always capture substandard individuals disproportionately from prey populations? Ecology 68, 669-674. doi: $10.2307 / 1938472$

Thomson, P. C., and Algar, D. (2000). The uptake of dried meat baits by foxes and investigations of baiting rates in Western Australia. Wildlife Research 27, 451-456. doi:10.1071/WR99034

Thomson, P. C., Marlow, N. J., Rose, K., and Kok, N. E. (2000). The effectiveness of a large-scale baiting campaign and the evaluation of a buffer zone strategy in Western Australia. Wildlife Research 27, 465-472. doi:10.1071/WR99036

Wirsing, A. J., Steury, T. D., and Murray, D. L. (2002). Relationship between body condition and vulnerability to predation in red squirrels and snowshoe hares. Journal of Mammalogy 83, 707-715. doi:10.1644/ 1545-1542(2002)083<0707:RBBCAV>2.0.CO;2

Woinarski, J. C. Z., and Braithwaite, R. W. (1990). Conservation foci for Australian birds and mammals. Search 21, 65-68.

Wood Jones, F. (1923-25). 'The Mammals of South Australia, Parts I-III.' (Government Printer: Adelaide.)

Manuscript received 16 April 2009, accepted 12 December 2009 


\section{Appendix 1}

\section{Potential predation rates and sustainability of Wheatbelt rock-wallaby populations}

Two populations of rock-wallabies (RW), Nangeen Hill and Mount Caroline, predator-baited from 1982 have stabilised at carrying capacity (K). This is evident from the census data and obvious signs of overgrazing (C. Pentland and R. Inglis, unpubl. data). Furthermore, a dispersal event was detected and linked to Mount Caroline.

On Mount Caroline from 2001 to 2007, 136 RW were trapped and translocated to sites where they formerly occurred (Table 1). This was done in an effort to mitigate the damage to nearby crops caused by RW; however, despite these removals, the population by 2009 (300+, N. Willers, pers. comm.) was comparable to the 1998 census of 296.

These removals, in effect, can be treated as an example of 'management predation', and therefore, an average of 19 wallabies per year were removed during a 7-year period, without precipitating a permanent population decline. Given this 25 -year dataset, we pose the following question: what is the theoretical level of predation that can be sustained by a population of $n$ RW individuals? We treat this as an exercise in determining the maximum sustainable harvest for a population that grows according to the logistic model as outlined in Skalski et al. (2005). Logistic growth is never perfect in small populations, but is an approximation that can provide some guidance for managers.

We apply the following formula (Skalski et al. 2005: p. 20):

$$
\text { Maximum sustainable harvest }(\mathrm{MSH})=\left(\left(\lambda_{\max }-1\right) \times \mathrm{K}\right) / 4 \text {, }
$$

where, $\ln \lambda_{\max }=r$ is the annual growth-rate estimate calculated from the early stages of the population recoveries.

Note that $\lambda_{\max }$ is derived from $\lambda^{t}=N_{t} / N_{\mathrm{o}}$, where $N_{t}$ is the population size at time $t$, and $N_{\mathrm{o}}$ is the population size at the commencement of predator baiting. For Mount Caroline, $N_{\mathrm{o}}$ is 13 (1982 census), $N_{t}$ is 42 (1986), $t=4$ (years) and K is 300 (Kinnear et al. 1988, and see text). Values of $\lambda_{\max }=1.34$ and $\mathrm{MSH}=26$ imply a maximum sustained harvest of $26 \mathrm{RWs}$ and this would be achieved by a Mount Caroline population of 150 individuals $(\mathrm{K} / 2)$. We note that the average management predation rate during 2001-07 was 19 , which was too low to effect a sustained population reduction. For Nangeen Hill, the data are $N_{\mathrm{o}}=29$ (1982), $N_{t=75}(1986)$ and $t=4$ (ibid). $\lambda_{\max }$ is found to be 1.27 and $\mathrm{MSH}=8$.

It is instructive to calculate the values for MSH, given a range of RW population sizes. For example, taking the average of $\lambda_{\max }$ values (1.305, and assuming logistic growth) and if the RW population is 10 , the MSH is 0.76 ; if it is 20 , the MSH is 1.5 . To enable population growth by small populations (i.e. 25 or less), effective predator control thus needs to be virtually absolute initially. This does not necessarily mean that every fox needs to be killed immediately after a baiting because they might be killed subsequently before any damage has occurred (see Thomson et al. 2000). It is also possible that only certain foxes are doing the killing, and only they need to be killed.

To summarise, this exercise highlights the following three points: (1) by inference, the RW fox-baiting protocol must be extraordinarily effective to allow population growth of small populations which has been repeatedly observed; (2) larger populations can tolerate a finite level of mortality caused by predators; and (3) the potential of contact telemetry to resolve such issues. 